\title{
Bone marrow aplasia following donor lymphocyte infusion in 4-year-old patient with chronic granulomatous disease after allogeneic stem cell transplantation: case report
}

\author{
MAGDALENA CIENKUSZI, MONIKA LEJMAN², NEL DĄBROWSKA-LEONIK ${ }^{3}$, MARTA CHOMA ${ }^{l}$, \\ KATARZYNA DRABKO ${ }^{1}$ \\ ${ }^{1}$ Department of Pediatric Hematology, Oncology and Transplantology, Medical University, Lublin, Poland \\ ${ }^{2}$ Laboratory of Genetic Diagnostics, Medical University, Lublin, Poland \\ ${ }^{3}$ Department of Immunology, Children's Memorial Health Institute, Warsaw, Poland
}

\begin{abstract}
Donor lymphocyte infusion (DLI) is typically used in 3 clinical situations: therapeutically for proven relapse of malignancy, prophylactically in patients with high-risk of relapse, and in case of mixed chimerism. Mixed chimerism, which occur after transplantation can be a sign of possible rejection. In case of increased mixed chimerism, immunotherapy with donor lymphocyte infusions could reverse this process. After DLI, both acute and chronic graft-versus-host disease and marrow aplasia are wellknown toxicities. In this paper, we present a case report of young patient with chronic granulomatous disease (CGD) after allogeneic hematopoietic stem cell transplantation (allo-HSCT), with successful immunotherapy following mixed chimerism, which was complicated by bone marrow aplasia that required a second stem cell infusion. DLI seems to be an effective and highly promising treatment method of transplant rejection in patients with CGD but can induce bone marrow aplasia and may require a second stem cell infusion.
\end{abstract}

Key words: children, hematopoietic stem cell transplantation, chronic granulomatous disease, donor lymphocyte infusion, bone marrow aplasia.

(Cent Eur J Immunol 2020; 45 (3): 346-350)

\section{Introduction}

Chronic granulomatous disease (CGD) is a rare inherited immune deficiency caused by mutations in the genes CYBB, NCF1, NCF2, NCF4, or CYBA, encoding one of the NADPH oxidase subunits (gp91phox, p47phox, p67phox, p40phox, p22phox) [1-3]. Typical manifestations are recurrent bacterial and fungal infections causing diarrhea, growth failure, lung disease, and granuloma formation in different organs. This defect occurs with estimated frequency of one in 250,000 individuals [4, 5]. CGD could be diagnosed with granulocyte function tests showing impaired phagocytic activity, such as dihydrorhodamine (DHR) flow cytometry burst assay or nitro blue tetrazolium reduction tests (NBT) [6]. Conventional treatment consists of anti-infectious prophylaxis with antibiotics and antimycotics, steroids, interferon $\gamma$ (IFN- $\gamma$ ); however, the outcomes are still unsatisfactory. The annual mortality rate is $2-5 \%$, and only $50 \%$ of patients with CGD reaches the age of $30[1,7,8]$.

Allogeneic hematopoietic stem cell transplantation (allo-HSCT) has been used in patients with chronic granulomatous disease since 1976 with various results [9-11]. Nowadays, HSCT from a matched donor is a safer procedure, if performed before chronic infections and severe organ damage [2, 8, 12]. The European Society for Blood and Marrow Transplantation (EBMT) suggests that patients with CGD require toxicity-reduced conditioning [13]. The risk of toxic complications of this regimen is lower than that associated with conventional procedures, but it may increase a risk of graft rejection. Mixed chimerism occurring after transplantation can be a sign of possible rejection. In case of increased mixed chimerism,

Correspondence: Magdalena Cienkusz, MD PhD, Department of Pediatric Hematology, Oncology and Transplantology, Medical University, Lublin, Poland, 6 Prof. Antoni Gębala St., 20-093 Lublin, Poland, e-mail: magdalena.cienkusz@wp.pl Submitted: 16.07.2018; Accepted: 3.10.2018 
immunotherapy with donor lymphocyte infusions (DLI) could reverse this process [14]. Donor T cells cause immunologic clearance of residual host lymphocytes and stem cells, allowing engraftment and growth of the donor stem cells $[15,16]$. Donor lymphocyte infusion is typically used in 3 clinical situations: therapeutically for proven relapse of malignancy, prophylactically in patients with high-risk of relapse, and in case of mixed chimerism. The main complications after DLI are graft-versus-host disease (GVHD), with $4-61 \%$ of cases and bone marrow aplasia occurring in $30-40 \%$ of CML [17].

We present a case report of a young patient with CGD after allo-HSCT, with successful immunotherapy following mixed chimerism, which was complicated by bone marrow aplasia that required a second stem cell infusion. Written informed consent was obtained from the patient's parents for publication of this case report.

\section{Case report}

A 3.5-year-old boy was diagnosed as CGD at the Department of Immunology of the Children's Memorial Health Institute in Warsaw. In the medical history, the first symptoms of the disease were present six months earlier and included lymphadenopathy with multiple abscesses of lymph nodes, recurrent severe pulmonary infections, diarrhea, cutaneous granulomas, and hepatosplenomegaly. NADPH-oxidase activity in stimulated neutrophils was absent in DHR flow cytometry burst assay, NBT was $1 \%$, and stimulated NBT $>150$ was $0 \%, 50-150$ was $0 \%$,
$20-50$ was $0 \%$, and 0 was $100 \%$. Molecular analysis by next generation sequencing (NGS) detected CYBB mutation on the $\mathrm{X}$ chromosome. Due to serious infectious and significant malnutrition, which required parenteral nutrition, in this case, the decision to proceed with HSCT was made immediately after the diagnosis.

Coexisting conditions included celiac disease, hypothyroidism, thrombophilia (factor V Leiden mutation), and non-specific inflammation of duodenum and colon. Total neutrophil and leukocyte counts, peripheral blood lymphocyte phenotyping by flow cytometer, serum immunoglobulin levels, and other biochemistry results were normal. The family history of primary immunodeficiency was irrelevant.

Pretransplant treatment included anti-infection prophylaxis with antibiotics and antimycotics, immunosuppression with steroids and azathioprine, and substitution of levothyroxine.

A transplant from matched unrelated donor was performed at the age of 4 years. The reduced toxicity conditioning regimen consisted of treosulfan at the total dose of $42 \mathrm{~g}$ per square meter, fludarabine at the total dose of $150 \mathrm{mg}$ per square meter, and thiotepa at the total dose of $10 \mathrm{mg}$ per kilogram. As GVHD prophylaxis, the patient received cyclosporine A, anti-T lymphocyte globulin (ATG), and mycophenolate mophetil. A total of $5 \times 10^{6} \mathrm{CD} 34+$ bone marrow stem cells per kilogram were infused.

Engraftment was achieved on day +19 , and full donor-derived hemopoietic chimerism using quantitative fluorescent PCR assays (QF-PCR) and short tandem re-

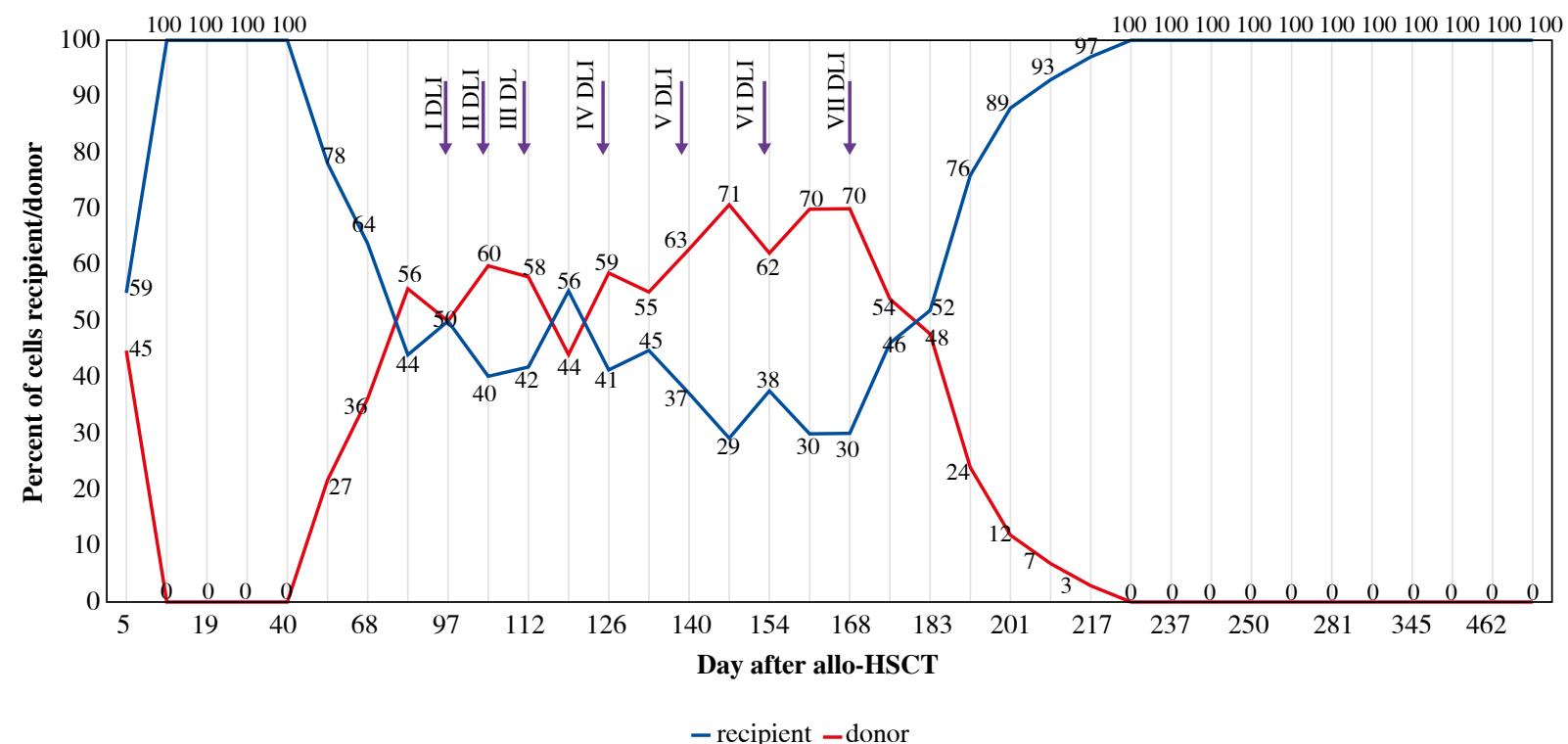

Fig. 1. Kinetics of cellular chimerism after the first allo-hematopoietic stem cell transplantation (allo-HSCT) and donor lymphocyte infusion (DLI) 
Table 1. Detailed information on the donor lymphocyte infusions (DLI)

\begin{tabular}{lccccccc}
\hline $\begin{array}{l}\text { No. of } \\
\text { DLI }\end{array}$ & No. of CD3+ cells & $\begin{array}{c}\text { Day after the } \\
\text { first allo- } \\
\text { HSCT }\end{array}$ & $\begin{array}{c}\text { Chimerism } \\
\% \text { donor cells }\end{array}$ & $\begin{array}{c}\text { ALT } \\
(\mathbf{U} / \mathbf{l})\end{array}$ & $\begin{array}{c}\text { AST } \\
(\mathbf{U} / \mathbf{l})\end{array}$ & $\begin{array}{c}\text { Urea } \\
(\mathbf{m g} / \mathbf{d l})\end{array}$ & $\begin{array}{c}\text { Creatinine } \\
(\mathbf{m g} / \mathbf{d l})\end{array}$ \\
\hline 1 & $1 \times 10^{6} / \mathrm{kg}$ & +98 & 50 & 25 & 29 & 16 & 0.3 \\
\hline 2 & $1 \times 10^{6} / \mathrm{kg}$ & +106 & 40 & 31 & 36 & 14 & 0.3 \\
\hline 3 & $1 \times 10^{7} / \mathrm{kg}$ & +113 & 42 & 40 & 47 & 20.1 & 0.3 \\
\hline 4 & $1 \times 10^{7} / \mathrm{kg}$ & +126 & 41 & 20 & 27 & 19 & 0.3 \\
\hline 5 & $50 \times 10^{6} / \mathrm{kg}$ & +140 & 37 & 17 & 22 & 24 & 0.4 \\
\hline 6 & $50 \times 10^{8} / \mathrm{kg}$ & +154 & 38 & 16 & 24 & 26 & 0.3 \\
\hline 7 & $100 \times 10^{8} / \mathrm{kg}$ & +168 & 30 & 18 & 24 & 21 & 0.3 \\
\hline
\end{tabular}

allo-HSCT - hematopoietic stem cell transplantation, PLT - platelets

Table 2. Laboratory test and chimerism before and after the second allo-hematopoietic stem cell transplantation (allo-HSCT)

\begin{tabular}{lcccccccc}
\hline $\begin{array}{l}\text { Day after } \\
\text { the first } \\
\text { allo-HSCT }\end{array}$ & $\begin{array}{c}\text { Day after } \\
\text { the second } \\
\text { allo-HSCT }\end{array}$ & $\begin{array}{c}\mathbf{\%} \\
\text { donor } \\
\text { cells }\end{array}$ & $\begin{array}{c}\text { No. of } \\
\mathbf{R B C} \\
(\times \mathbf{1 0} / \mathbf{u l})\end{array}$ & $\begin{array}{c}\text { No. of HG } \\
(\mathbf{g} / \mathbf{d l})\end{array}$ & $\begin{array}{c}\text { No. of WBC } \\
(\times \mathbf{1 0} / \mathbf{u l})\end{array}$ & $\begin{array}{c}\text { No. of NEUTR } \\
\left(\times \mathbf{1 0}^{3} / \mathbf{u l}\right)\end{array}$ & $\begin{array}{c}\text { No. of PLT } \\
(\times \mathbf{1 0} / \mathbf{u l})\end{array}$ & $\begin{array}{c}\text { IgG } \\
(\mathbf{g} / \mathbf{d l})\end{array}$ \\
\hline+196 & 78 & $\mathbf{2 . 8 6}$ & $\mathbf{6 . 7}$ & 1.82 & $\mathbf{0 . 0 8}$ & $\mathbf{5 3}$ & 7.15 \\
\hline+208 & 93 & 3.17 & $\mathbf{8 . 0}$ & 1.11 & $\mathbf{0 . 0 1}$ & $\mathbf{4}$ & 7.12 \\
\hline+221 & 100 & 3.57 & 9.2 & $\mathbf{0 . 7 3}$ & $\mathbf{0 . 0 1}$ & $\mathbf{3 0}$ & - \\
\hline+230 & 100 & 3.88 & 10.1 & $\mathbf{0 . 6 8}$ & $\mathbf{0 . 0 1}$ & $\mathbf{3 6}$ & 5.73 \\
\hline & 100 & $\mathbf{2 . 2 9}$ & $\mathbf{5 . 8}$ & $\mathbf{0 . 5 8}$ & $\mathbf{0 . 0 1}$ & $\mathbf{7}$ & - \\
\hline & +6 & 100 & 3.83 & 10.6 & 3.38 & 1.83 & $\mathbf{2 4}$ & - \\
\hline+20 & 100 & 3.53 & 10.0 & 2.70 & 0.58 & 64 & $\mathbf{4 . 2 4}$ \\
\hline+51 & 100 & 4.02 & 11.6 & 5.25 & 1.77 & 91 & $\mathbf{4 . 2 0}$ \\
\hline+87 & 100 & 4.04 & 11.5 & 6.10 & 2.77 & 102 & $\mathbf{4 . 8 7}$ \\
\hline+115 & 100 & 4.33 & 11.8 & 6.79 & 3.00 & 139 & 6.04 \\
\hline+143 & 100 & 6.41 & 13.0 & 8.42 & 1.6 & 129 & 5.34 \\
\hline
\end{tabular}

peats (STR) was noted on day +12 for the first time. The early post- transplant period was complicated on day +2 by acute ileus with unknown etiology, which did not require surgical intervention. The patient presented acute GVHD of grade I, involving the skin and oral mucosa from day +26 , which did not require treatment. Molecular analysis of peripheral blood revealed $100 \%$ of donor cells weekly to day +40 . The patient was discharged in a particularly good condition on day +43 post-transplant. The presence of oxidase-positive neutrophils in DHR flow cytometry burst assay was $90.8 \%$ (0.91 index) on day +51 .

On day +57 , mixed chimerism occurred in peripheral blood with tendency to increase (Fig. 1), but general clinical condition of the patient was good and blood counts were normal. Based on those results, cyclosporine A was discontinued on day +68 , but the recipient signal was systematically growing. As the next immunotherapeutic inter- vention, we decided to perform DLI. DLI started on day +98 and the patient was given 7 increasing doses every 4 weeks. During those procedures, chimerism was still mixed with decreasing donor signal, and DHR flow cytometry burst assay was positive in $19.5 \%$ ( 0.2 index) on day +176 . Detailed information on infusions are presented in Table 1 .

The features of pancytopenia occurred on day +186 and the patient was admitted to hospital. The boy required transfusions of red cell concentrate (RCC) and platelet concentrate (PC), but his general condition was good, with no signs of infection and no symptoms of GVHD. Chimerism was checked every week and a slow increase in the donor signal was noticed, until full chimerism was obtained on day +221 ; unfortunately, there was no hematological recovery by this point. Bone marrow biopsy confirmed aplasia with full donor chimerism in bone 
marrow. We started administration of G-CSF with no effect. A decision was made to proceed with a second stem cell infusion from the same donor without conditioning, and it was performed 8 months after the first HSCT. No post-transplant immunosuppression was used. G-CSF was given from day +4 after the second HSCT and on day +20 , a recovery of neutrophils and reticulocytes was noticed (Table 2). The presence of oxidase-positive neutrophils by DHR flow cytometry burst assay tested on day +45 after the second HSCT showed 95.3\% (1.06 index). The patient was followed by an outpatient schedule and required only routine anti-infection prophylaxis and immunoglobulin substitution.

At 12 months after immunotherapy, chronic GVHD limited to the skin occurred and the patient was treated with steroids and cyclosporine A. At 9 months after the patient's second allo-HSCT, his general condition was good, with stable engraftment, $100 \%$ of donor cells, and the presence of oxidase-positive neutrophils in DHR flow cytometry burst assay.

\section{Discussion}

Allo-HSCT is the only curative treatment for CGD, and experimental gene therapies in clinical trials are not available for every patient. The standard treatment consisting of lifelong anti-infectious prophylaxis, steroids, and interferon gamma may lead to an occurrence of major organ failure as a result of prolonged toxic therapies. Moreover, a transplant is recommended only in severe cases, after the failure of conventional methods and when the patient is chronically ill [18]. Therefore, the time to initiate a transplant procedure in patients with CGD is still under discussion. Goździk et al. postulated that the appropriate moment to perform HSCT in young patients with proven diagnosis of CGD is before the onset of life-threatening infections [1]. Similarly, Kansoy et al. and Leung et al. claimed that bone marrow transplantation should be performed in the first years of life before development of irreversible organ damage [2, 18]. Seger et al. reported outcomes of 27 patients with CGD transplanted from 1985 to 2000, based on the European Bone Marrow Transplant Registry for primary immunodeficiencies. In their paper, most transplant recipients were children $(n=25)$ and survival rate was high, especially in patients without an infection at the moment of transplantation. In that group of patients, deaths occurred in 4 cases, with pre-existing fungal infections refractory in all conventional treatments [8]. In our opinion, allo-HSCT should be considered at every stage of treatment of CGD patients, also immediately after diagnosis.

Toxicity-reduced conditioning, especially in patients with irreversible organ damage, can provide an engraftment with minimal complications. However, on the other hand, this procedure increases the risk of incomplete engraftment or graft rejection and GVHD. Such was the case of our patient, who had mixed chimerism after allo-HSCT with reduced conditioning, and symptoms of rejection could be reversed by donor lymphocyte infusions.

After DLI, both acute and chronic graft-versus-host disease and marrow aplasia are well-known toxicities [17]. These complications were reported in about $30-45 \%$ of patients treated with DLI $[17,19]$. Our patient did not show any side effects of infusion, and only limited skin GVHD occurred within one year after DLI. Four months after the first infusion, the patient achieved full donor-derived hemopoietic chimerism, unfortunately resulting in pancytopenia, which could be managed with the second transplant from the same donor without conditioning. The mechanism of bone marrow aplasia after DLI is not fully understood. Hematologic recovery depends on the presence of hematopoietic progenitors. Most likely, DLI damages residual host hematopoiesis before recovery of donor hematopoiesis. In case of marrow failure, second stem cell infusion could reverse pancytopenia, as in our patient [19].

Mixed chimerism does not necessarily lead to recurrence of disease symptoms. The donor cells can effectively mask the defect in superoxide-producing NADPH oxidase of the recipient's neutrophils. Kansoy et al. presented a case report of an 8-month-old boy with CGD after allo-HSCT, whose chimerism in peripheral blood was $50 \%$ of donor cells at five years after the transplantation, and $85 \%$ of his neutrophils had normal oxidative burst activity. During the 60 months of follow-up, this young patient had no severe infectious disease, was generally in very good health condition, and growing properly [2]. In contrast, NADPH-oxidase activity in stimulated neutrophils was absent in our patient who had between $30-52 \%$ of donor cells in the serum. Therefore, the decision to use an immunotherapeutic intervention should be made not only on the analysis of chimerism, but also on the assessment of severity of symptoms of the underlying disease and unacceptable results of oxidative burst activity.

In the literature, reports on donor lymphocyte infusion at unstable mixed chimerism after allogeneic stem cells transplantation for non-malignant disorders mainly consider patients with thalassemia, sickle cell anemia, or hemoglobinopathies [20-22]. The effectiveness of DLI therapy was reported in a few cases of children with chronic granulomatous disease $[1,8,11,14,23]$. None of those reviews reported complications such as bone marrow aplasia, which was observed in our patient after DLI. Horwitz et al. reported 10 patients ( 5 children, 5 adults) with CGD, who underwent HSCT followed by DLI at 30 days or more after the transplantation. The median follow-up time was 17 months. During this period, infections like fungal pneumonia, herpes zoster keratitis, pneumococcal sepsis, or lymphoproliferative disorder due to EBV, occurred in 4 cases. None of those patients had pancytopenia [14]. Akioka et al. described an effective DLI at unstable mixed chimerism after HSCT in a 14-year-old male with CGD. 
The post-DLI period was complicated only by an acute hepatic GVHD [23]. Nagler et al. presented a case of a boy suffering from chronic granulomatous disease, who underwent HSCT, and the mixed chimerism was the reason for the use of DLI after which, no side effects were observed [11]. Similarly to our patient, Goździk et al. described a patient who underwent HSCT twice (patient no. 1). However, in contrast to our case, the reason why the second transplantation of bone marrow cells was performed was the rejection of transplant despite the use of DLI, not bone marrow aplasia or other hematological complications [1]. Therefore, in our opinion, this case is exceptional.

\section{Conclusions}

DLI seems to be an effective and highly promising method of treatment of transplant rejection in patients with CGD but can induce bone marrow aplasia and may require a second stem cell infusion.

\section{The authors declare no conflict of interest.}

\section{References}

1. Goździk J, Pituch-Noworolska A, Skoczeń S, et al. (2011): Allogeneic haematopoietic stem cell transplantation as therapy for chronic granulomatous disease-single centre experience. J Clin Immunol 31: 332-337.

2. Kansoy S, Kutukculer N, Aksoylar S, et al. (2006): Successful bone marrow transplantation in an 8-month-old patient with chronic granulomatous disease. Turk J Pediatr 48: 253-255.

3. Leiding JW, Holland SM (2016): Chronic granulomatous disease. GeneReviews [internet]. https://www.ncbi.nlm.nih.gov/ books/NBK99496/.

4. Winelstein JA, Marino MC, Johnston RB, et al. (2000): Chronic granulomatous disease. Report on a national registry of 368 patients. Medicine (Baltimore) 79: 155-169.

5. Van der Berg JM, van der Koppen E, Ahlin A, et al. (2009): Chronic granulomatous disease: the European experience. PlosOne 4: e5234.

6. Siedlar M (2017): Chronic granulomatous disease. In: Wybrane zagadnienia z pierwotnych niedoborów odporności oraz diagnostyki immunologicznej, Pietrzyk JJ, Kwinta P (eds). Wydawnictwo Uniwersytetu Jagiellońskiego, Kraków: 72-74.

7. Margolis DM, Melnick DA, Alling DW, et al. (1990): Trimethoprim-sulfamethoxazole prophylaxis in the management of chronic granulomatous disease. J Infect Dis 162: 723-726.

8. Seger RA, Gungor T, Belohradsky BH, et al. (2002): Treatment of chronic granulomatous disease with myeloablative conditioning and an unmodified hemopoietic allograft: a survey of the European experience, 1985-2000. Blood 100: 4344-4350.

9. Foroozanfar N, Hobbs JR, Hugh-Jones K, et al. (1977): Bone marrow transplantation from an unrelated donor for chronic granulomatous disease. Lancet 1: 210-213.

10. Kamani N, August CS, Douglas SD, et al. (1984): Bone marrow transplantation in chronic granulomatous disease. Pediatr 105: 42-46.
11. Nagler A, Ackerstein A, Kapelushinikj, et al. (1999): Donor lymphocyte infusion post-non-myeloablative allogeneic peripheral blood stem cell transplantation for chronic granulomatous disease. Bone Marrow Transplant 24: 339-342.

12. Calvino MC, Maldonado MS, Otheo E, et al. (1996): Bone marrow transplantation in chronic granulomatous disease. Eur J Pediatr 156: 877-879.

13. https://www.ebmt.org/sites/default/files/migration_legacy_ files/document/Inborn\%20Errors\%20Working\%20Party $\% 20$ ESID\%20EBMT\%20HSCT\%20Guidelines\%202017.pdf

14. Horwitz ME, Barrett J, Brown MR, et al. (2001): Treatment of chronic granulomatous disease with nonmyeloblative conditioning and a T-cell-depleted hematopoietic allograft. N Engl J Med 12: 881-888.

15. Sykes M, Sheard MA, Sachs DH (1988): Graft-versus-hostrelated immunosuppression is induced in mixed chimeras by alloresponses against either host or donor lymphohematopoietic cells. J Exp Med 168: 2391-2396.

16. Pelot MR, Pearson DA, Swenson K, et al. (1999): Lymphohematopoietic graft-vs.-host reactions can be induced without graft-vs.-host disease in murine mixed chimeras established with a cyclophosphamide-based nonmyeloablative conditioning regimen. Biol Blood Marrow Transplant 5: 133-143.

17. Castagna L, Sarina B, Bramanti S, et al. (2016): Donor lymphocyte infusion after allogeneic stem cell transplantation. Transfus Apher Sci 54: 345-355.

18. Leung TF, Chik K, Li C, et al. (1999): Bone marrow transplantation for chronic granulomatous disease: long-term follow-up and review of literature. Bone Marrow Transplant 24: 567-570.

19. Keil F, Haas OA, Fritsch G, et al. (1997): Donor leukocyte infusion for leukemic relapse after allogeneic marrow transplantation: lack of residual donor hematopoiesis predicts aplasia. Blood 89: 3113-3117.

20. Karasu GT, Yesilipek MA, Karauzum SB et al (2012): The value of donor lymphocyte infusions in thalassemia patients at imminent risk of graft rejection following stem cell transplantation. Pediatr Blood Cancer 58: 453-458.

21. Lucarelli G, Galimberti M, Polchi P, et al. (1990): Bone marrow transplantation in patients with thalassemia. $\mathrm{N}$ Engl J Med 322: 417-421.

22. Lucarelli G, Isgrň A, Sodani P, et al. (2012): Hematopoietic Stem Cell Transplantation in Thalassemia and Sickle Cell Anemia. Cold Spring Harb Perspect Med 2: 1-5.

23. Akioka S, Itoh H, Ueda I, et al. (1998): Donor lymphocyte infusion at unstable mixed chimerism in an allogeneic BMT recipient for chronic granulomataous disease. Bone Marrow Transplant 22: 609-611. 